\title{
On the Evolving Neurobiology of the Near-Death Experience: Comments on "A Neurobiological Model for Near-Death Experiences"
}

\author{
Daniel B. Carr, M.D. \\ Massachusetts General Hospital \\ and Harvard Medical School
}

I enjoyed reading the updating and extension by Juan C. SaavedraAguilar and Juan S. Gómez-Jeria of a hypothesis I advanced in this journal several years ago, that near-death experiences (NDEs) reflect limbic stress responses evoked by unusually robust releases of neurotransmitters such as endorphins (Carr, 1982). That hypothesis, itself an extension of others' earlier arguments along the same lines (Noyes and Kletti, 1976), was made possible by the discovery of opioid peptides in the mid-1970s and resultant knowledge spurt still under way (Carr, 1988).

In the context of my interest in the neurobiology of fever (Carr, 1979) and subsequent research on $\beta$-endorphin levels in human stress (Carr, Bullen, Skrinar, Arnold, Rosenblatt, Beitins, Martin, and McArthur, 1981; Carr, Sheehan, Surman, Greenblatt, Heninger, Jones, Spiro, Levine, and Watkins, 1986) or in animal models of critical illness (Carr, Bergland, Hamilton, Blume, Kasting, Arnold, Martin, and Rosenblatt, 1982; Hamilton, Carr, LaRovere and Black, 1986), it was only natural to frame the hypothesis at that time.

Dr. Carr is Assistant-in-Anesthesia and Clinical Assistant in Medicine at the Massachusetts General Hospital, and Associate Professor of Anesthesia and Medicine (Endocrinology) at Harvard Medical School. Requests for reprints should be addressed to Dr. Carr at the Department of Anesthesia, Massachusetts General Hospital, Boston, MA 02114. 
Subsequent results in a broad variety of disciplines, integrated in a scholarly manner by Saavedra-Aguilar and Gómez-Jeria, are both gratifying and frustrating. It is personally gratifying that progress in cognitive science and neurobiology have strengthened a model that proposes, to use their words, "that the NDE . . . arises from the abnormal functioning of . . portions of the central nervous system." In particular, this interim work has advanced the NDE's possible pathophysiological basis, offered relevant clinical correlates, and broadened its linguistic and cognitive underpinnings. On the other hand, these recent embellishments of the earlier model have not yet reified it. Even the authors' diagram, for all its clarity, depicts a plausible argument rather than a proven process.

Lest this judgment be deemed uncharitable, let me remind the reader that other complex perceptual processes, such as pain (Szyfelbein, Osgood, and Carr, 1985) and vision (Georgopoulos, Lurito, Petrides, Schwartz, and Massey, 1989), and experimental states such as anxiety (Carr and Sheehan, 1984; Carr, Sheehan, Surman, Greenblatt, Heninger, Jones, Spiro, Levine, and Watkins, 1986) and depression (Gold, Goodwin, and Chrousos, 1988) have been greatly clarified in recent years. Their neuroanatomy and neurochemistry (Anand and Carr, 1989), cellular and molecular mechanisms (Carr, 1988; Nicoll, 1988), and concurrent regional brain activation (Reiman, Fusselman, Fox, and Raichle, 1989) in vivo are well understood. Further, the biobehavioral actions of key mediators within the biological model of NDEs, such as corticotropin-releasing hormone (Taylor and Fishman, 1988), have been well elucidated in a very short time. Biological studies of NDEs suffer by comparison, perhaps because the field is in its infancy.

Many scientific disciplines share, I believe, certain features of their life cycles. In particular, dormancy at the fringes of mainstream science has been a common feature in the embryonic stages of currently "hot" research areas as diverse as chaos (Gleich, 1987), magnetic resonance imaging (Kleinfield, 1985), endorphin studies (Carr and Ballantyne, 1987), and anxiety (Sheehan, Carr, Fishman, Walsh, and PeltierSaxe, 1985). Workers in each area were scorned as eccentrics by their more conventional peers until a striking objective finding arose to capture their colleagues' attention. The yearly number of papers in each area, or researchers' hours, or grant funds awarded then typically rose sharply across several orders of magnitude, while each area coalesced with "big" science.

I am not sure, however, that research on the biological basis of NDEs will mature as these other areas have. Other than anecdotal case 
reports, or data acquired coincidentally during the course of other studies in critically ill patients who happen to die, clinical investigations to correlate patterns of stress hormone secretion with cognitive or experimental phenomena seem unethical and impossible. Animal studies, always subject to misinterpretation when essentially subjective phenomena are in question, are increasingly restricted because of activist pressure. Finally, there is no clear patent, device, or profit that would result from understanding NDEs' biological basis regardless of the benefit to our culture's collective wisdom. For these reasons the quest resembles other supremely important yet supremely difficult ones, such as defining the phylogeny or ontogeny of consciousness itself.

In summary, the commendable work of Saavedra-Aguilar and Gómez-Jeria makes me cautiously optimistic that a growing number of facts are consistent with an ever-more-precise model to "explain" NDEs. As these authors are aware, much more could be written about what it means to describe the flow of causality within any complex process, but that is a separate question (Carr, Jones, Bergland, Kasting, Hamilton, Fisher, Martin, and Rosenblatt, 1985; Carr, 1989). Precisely where these international efforts will lead is a mystery, but one that is seductive, satisfying to contemplate, and important to solve. To quote the philosopher Patricia Smith Churchland (1988, pp. 304-307):

Consistent with this progress, we may expect that philosophical problems about the mind will be productively addressed and perhaps radically transformed by a convergence of neuroscientific, psychological and computational research.... Making sense of ourselves is our enduring philosophical quest. What is exciting about this period in the history of science is that we may finally have the resources to succeed.

\section{References}

Anand, K. J. S., and Carr, D. B. (1989). The neuroanatomy, neurophysiology and neurochemistry of pain stress, and analgesia in newborns and children. In Schechter, N. L. (Ed.), The management of pain in children (Pediatric clinics of North America), Pp. 795-822. Philadelphia, PA: Saunders.

Carr, D. B. (1979). Endogenous opioids and fever. Perspectives in Biology and Medicine, 23, 1-6.

Carr, D. B. (1982). Pathophysiology of stress-induced limbic lobe dysfunction: A hypothesis for NDEs. Anabiosis: The Journal of Near-Death Studies, 2, 75-89.

Carr, D. B. (1988). Opioids. Pp. 273-287 in Firestone, L. (Ed.), Molecular basis of drug action in anesthesia (International anesthesia clinics, vol. 26). Boston, MA: Little, Brown. 
Carr, D. B. (1989). Causality, predictability and explanation. Theoretical Surgery, 4, 88-90.

Carr, D. B., and Ballantyne, J. C. (1987). Endorphins and analgesia. Comprehensive Therapy, 13, 7-13.

Carr, D. B., Bergland, R. M., Hamilton, A., Blume, H., Kasting, N. W., Arnold, M. A., Martin, J. B., and Rosenblatt, M. (1982). Endotoxin-stimulated opioid peptide secretion: Two secretory pools and feedback control in vivo. Science, 217, 845-848.

Carr, D. B., Bullen, B. A., Skrinar, G. S., Arnold, M. A., Rosenblatt, M., Beitins, I. Z., Martin, J. B., and McArthur, J. W. (1981). Physical conditioning facilitates the exercise-induced secretion of $\beta$-endorphin and $\beta$-lipotropin in women. New England Journal of Medicine, 305, 560-563.

Carr, D. B., Jones, K. J., Bergland, R. M., Kasting, N. W., Hamilton, A., Fisher, J. E., Martin, J. B., and Rosenblatt, M. (1985). Causal links between plasma and CSF endorphin levels in ovine endotoxin stress: Vector ARMA analysis. Peptides, 9, (Suppl. 1), 5-10.

Carr, D. B., and Sheehan, D. V. (1984). Panic anxiety: A new biological model. Journal of Clinical Psychiatry, 45, 323-330.

Carr, D. B., Sheehan, D. V., Surman, O. S., Greenblatt, D. J., Heninger, G. R., Jones, K. J., Spiro, T., Levine, P. H., and Watkins, W. D. (1986). Neuroendocrine correlates of lactate-induced panic and their response to chronic alprazolam therapy. American Journal of Psychiatry, 143, 483-494.

Churchland, P. S. (1988). The significance of neuroscience for philosophy. Trends in Neurosciences, 11, 304-307.

Georgopoulos, A. P., Lurito, J. T., Petrides, M., Schwartz, A. B., and Massey, J. T. (1989). Mental rotation of the neuronal population vector. Science, 243, 234-236.

Gleich, J. (1987). Chaos: Making a new science. New York, NY: Viking.

Gold, P. W., Goodwin, F. K., and Chrousos, G. P. (1988). Clinical and biochemical manifestations of depression: Relation to the neurobiology of stress (Part two). New England Journal of Medicine, 319, 413-420.

Hamilton, A. J., Carr, D. B., LaRovere, J. M., and Black, P. McL. (1986). Endotoxic shock elicits greater endorphin secretion than hemorrhage. Circulatory Shock, 19, 47-54.

Kleinfield, S. (1985). A machine called indomitable. New York, NY: Times Books.

Nicoll, R. (1988). The coupling of neurotransmitter receptors to ion channels in the brain. Science, 241, 545-551.

Noyes, R., Jr., and Keltti, R. (1976). Depersonalization in the face of life-threatening danger: An interpretation. Omega, 7, 103-104.

Reiman, E. M., Fusselman, M. J., Fox, P. T., and Raichle, M. E. (1989). Neuroanatomical correlates of anticipatory anxiety. Science, 243, 1071-1074.

Sheehan, D. V., Carr, D. B., Fishman, S. M., Walsh, M. M., and Peltier-Saxe, D. (1985). Lactate infusion in anxiety research: Its evolution and practice. Journal of Clinical Psychiatry, 46, 158-165.

Szyfelbein, S. K., Osgood, P. F., and Carr, D. B. (1985). Pain assessment and plasma $\beta$-endorphin levels in burned children. Pain, 22, 173-182.

Taylor, L., and Fishman, L. M. (1988). Corticotropin-releasing hormone. New England Journal of Medicine, 319, 213-222. 